Saemisch Handbuch, p. 281) states "die Brillen für Kurzsichtigkeit kamen erst um die Mitte des 16ste Jahrhunderts auf. Papst Leo $\mathrm{X}$ ist in 1457 mit seinem Konkav-glas von Rafael gemalt worden. In der Perspectiva Communis von Joannes Archiepisc. Cantuar., 1542, werden sie erlautert." Dr. Charles Singer also notes the coincidence and considers Peckham as possibly directly influenced by Bacon. He says of the former in. Vol. II. of his Studies in the History and Method of Science, 1921, that "his views are mainly derived from Al Hazen, though perhaps partly from Bacon. His work was important as having drawn wide attention to optical principles, and from the fact that he refers to the possibility of concave glasses."

We have done our best to show that in coincidences of time and place we have much to support the intrinsic evidence of interaction between the two philosophers, though the final proof of priority of discovery, the date of publication, must of necessity be always lacking in data given to the world in manuscript only. In any case it is pleasant to reflect that, in spite of the accumulation of ignorance and prejudice which was the burden of the Middle Ages, there were already here and there men whose search for truth and whose interchange of ideas laid the foundation for our later learning and whose attitude of mind and practical knowledge bore a much greater resemblance to our own than we sometimes stop to think.

\title{
CATERPILLAR HAIR OPHTHALMITIS (OPHTHALMIA NODOSA)
}

\author{
BY \\ R. Foster MOORE \\ LONDON
}

CASES of serious damage to the eyes as a result of penetration by caterpillar hairs, are well recognised, but are of considerable rarity. It is worth while, therefore, to report the following case which recently came under my care.

A boy, aged 12 years, came to the Moorfields Eye Hospital on May 30,1928, with a sore right eye. His tale was that whilst at play fourteen days previously, another boy threw a caterpillar at him, which struck him in the eye. He was an intelligent boy, and when asked what caterpillar it was, immediately said a "woolly bear." He was at once admitted to hospital.

On examination his right eye was greatly inflamed, with a general diffuse injection of all the ocular vessels; there was no staining of the cornea. The anterior chamber was about a quarter full of pus, and numerous fine deposits were present on the back of the cornea. The pupil dilated freely. There was intolerance of 
light, which made examination a little difficult; sight was greatly impaired.

On examination with a corneal lens, three hairs, evidently from the caterpillar, were to be seen quite deeply embedded in the substance of the cornea. They were exceedingly fine, and owing to the inability of the patient to tolerate examination, were not easily seen. It seemed likely that if one could get a better examination other hairs would be found, and this proved subsequently to be the case.

Mr. F. W. Law, the house surgeon, endeavoured to remove one of these hairs; he found, however, that as soon as an incision into the corneal substance was made, it became impossible any longer to see the hair.

No hairs were found in the conjunctiva, and no nodules were present at any time in the course of the disease, and consequently the usual term of "Ophthalmia Nodosa" has no point as applied to this particular case.

He remained in hospital for five weeks and was frequently examined by many observers during his stay. Intolerance of light was a marked feature. The hypopyon disappeared in a few days, but he had very considerable exudate into the vitreous which was slow in clearing; it had, however, cleared to a large extent five weeks later, leaving rather gross floating opacities. The keratic precipitates were soon much reduced in number and size, but were still quite copious on his discharge, at which time the fundus was seen fairly easily, and nothing abnormal was discovered in it; his visual acuity was $6 / 12$.

Previous to leaving hospital slit-lamp examination became possible, and several additional hairs were discovered by its means ; all of them extended quite deeply into the substantia propria. It was not possible to make out their structure, as to whether they were barbed or not.*

The future history was one of progressive and uninterrupted recovery, and the recurrences which have been spoken of as a marked feature of the condition, did not occur. I last saw him on September 1, that is three and a half months after the time of the accident, when the eye was quite quiet, entirely free of inflammation, the hairs could still be seen, and I could not satisfy myself that they had shifted their position, though I should be quite unable to be sure that they had not done so. No nodules were present; there were no adhesions of the iris; I could see no fundus disease, and his visual acuity was $6 / 6$.

* There is no evidence that the hairs were those of a " woolly bear," except the boy's statement, and indeed one's impression was that they seemed to be too fine for the bulk of the hairs of the "woolly bear" caterpillar, and as stated below, the barbing of these hairs would seem to offer a powerful bar to their penetration. 
Mr. J. B. Lawford, in the "Transactions of the Ophthalmological Society," 1895, Volume XV, p. 210, reports a case of this condition with his usual thoroughness and accuracy, and in doing so surveys the literature up to that time. In the twelve years preceding, he was able to discover eight reliable cases. The features that he points out as being outstanding are the following:

Firstly, the subsidence of the symptoms which follow immediately upon the injury, with a later recrudescence, so that in only one case was the interval between the accident and the date at which the patient was first seen by an ophthalmic surgeon less than two months. His patient, however, like the present one, came under observation two weeks after the injury.

Secondly, there are the usual signs of irido-cyclitis.

Thirdly he says the most noteworthy feature consists in the presence of nodules in the conjunctiva episcleralis. The favourite site appears to be the ocular conjunctiva, between the lower border of the cornea and the fornix They had varied in number from three to twenty-six. The nodules are round or oval, flattened, grey or yellowish, and semi-translucent in appearance, firm when touched with the finger, their size being variously given as that of millet seeds, or 1 to $2 \mathrm{~mm}$. in diameter.

He quotes Becker as saying that these nodules do not develop in man till three months after the injury to the eye; they were, however, present in Lawford's case three weeks after the accident. It will be seen that in the present case none were visible three and a half months after the accident, and the eye was quite white and had apparently completely recovered.

The subsequent history of a case, according to Lawford, is one of repeated remissions and exacerbations, and he states that in all the recorded cases, including his own, a period of at least six months had elapsed before the symptoms entirely disappeared.

The present case is again an exception in this respect, for although during the first week or two the condition of the inflammation varied somewhat, on the whole, so soon as obvious improvement set in progress was slow but uninterrupted.

Lawford states with regard to the prognosis that it must be guarded, that there may be such severe structural change as may lead to serious damage to the sight, but that in none of the reported cases has the eye been destroyed. The recovery in the present case may be considered to have been complete, and the visual acuity fully restored, as also occurred in his own case.

How extraordinarily sharp must be the point of such flexile structures as these hairs, in order that they shall penetrate quite deeply so tough a structure as the cornea! The fineness of them is borne in upon one when they are examined in the cornea by means of the slit-lamp. 
I am indebted to Mr. J. E. H. Roberts, whose exceptional knowledge on these matters is so well known, for much interesting information about caterpillar hairs. He has shown me under the microscope that the hairs of the woolly bear caterpillar, that is, the larva of the tiger moth, are all of them coarsely barbed, and indeed this can easily be seen with an ordinary corneal lens, but it is a curious fact that the barbs point, not as one would expect, backwards, so as to facilitate the penetration of the hair, but forwards, towards its point, and would therefore seem to be planned to prevent their penetration.

It has been suggested that the hairs are capable of migration in the tissues of the eye; were the barbs directed so as to point away from the point of the hair, this phenomenon would seem likely, but arranged as they are, it would seem to be almost impossible of occurrence. In the case of the gold-tailed moth, Eltringham's diagrams show the barbs pointing away from the point of the hair, and so it would seem migration in that case might well occur.

It has been suggested that the hairs contain some form of poison, and in confirmation of this it is stated that they are much less irritating after being washed with alcohol, and that the alcoholic washings possess irritating properties, and further, that hairs taken from a dead caterpillar produce much less severe lesions than do those from the living larva. These observations, however, have been disputed, and appear to be lacking in verification. At the same time, it would seem that the severity of the inflammation with the formation of hypopyon, and its long course, extending into months, would strongly suggest that it was not due simply to the presence of a small, inert, foreign substance in the cornea, but that some potent poison was responsible for it.

\title{
FRAME FITTING BY PHOTOGRAPHY
}

\author{
BY \\ ERNEST E. MADDOX \\ BOURNEMOUTH
}

THE corneae and pupils are, as we know, misleading indices for the fitting of frames and especially for bifocals. The only rational criteria are the points on the two corneae which the visual axes traverse, and which the squint camera, details of which I published thirty years ago*, mapped out by what we might call " circumlental photography," that is to say, by surrounding the lens of the camera with a reflecting or brightly illuminated surface so as

* Ocular Muscles-1st edition, p. 333, 2nd edition, p. 209. 